\title{
A COLONIZAÇÃO DO NORTE DO PARANÁ: organização, catalogação e análise dos documentos da coleção de George Craig Smith (1909-1992)
}

Raimunda de Brito Batista Regina Maria G. Domiciano

\section{DA INTRODUÇÃO, DESCRIÇÃO E ORGANIZAÇÃO DO MATERIAL}

A colonização do norte do Paraná faz parte do processo que se desdobrou em descobertas, tomada de posse, exploração, povoamento e independência, um processo matriz, recorrente em todo o processo de colonização das Américas. A transformação do acontecimento em fato histórico dá-se através dos registros. Os meios usados para registrar os acontecimentos desse processo em fatos históricos foram: as cartas, os ofícios, os mapas, os diários, os livros-caixa, entre outros.

Os chamados colonizadores da região norte do Paraná tiveram o cuidado de guardar e preservar os documentos pessoais, os objetos de trabalho, e doaram parte desse material ao recém-criado Museu Histórico de Londrina Padre Carlos Weiss. Muitos desses colonizadores também doaram parte de sua correspondência pessoal, e esses documentos estão escritos nas suas línguas de origem. A maioria deles não foi ainda traduzida nem analisada, tornando-se uma barreira para o pesquisador da história da região. Essa documentação está depositada no setor de Biblioteca e Documentação do museu. São documentos que possuem informações valiosas para explicar as várias faces do processo de colonização da região norte do Paraná.

O nosso interesse voltou-se para a documentação da coleção de George Craig Smith, agenciador de terras da Companhia de Terras Norte do Paraná (CTNP). Esse cidadão, paulista, filho de ingleses, manteve uma correspondência considerável, durante toda a vida, o que constitui uma fonte de inegável interesse histórico. Parte dessa correspondência, como se encontra em língua inglesa, foi traduzida durante os dois últimos 
anos de sua vida. Algumas das cartas foram traduzidas pelo próprio George Smith. Muitas outras ainda estão em processo de tradução e revisão. Ao mesmo tempo, as bibliotecárias do Museu Histórico elaboraram um breve resumo e indexação de outras cartas, representando $5 \%$ da coleção de um total de 5 mil documentos. Esse material está sendo acondicionado dentro de normas preestabelecidas para catalogação, como forma de preservar a vida útil do mesmo.

"A história cultural tal como a entendemos tem por principal objeto identificar o modo como, em diferentes lugares e momentos, uma determinada realidade social é construída, pensada, dada a ler." (Chartier, 1988) Para que se identifique uma determinada realidade, é necessário classificar, delimitar e organizar essa realidade e suas representações. A correspondência pessoal pode revelar visões de mundo significativas, que resultam em compreensão das idéias que circularam entre aqueles que vieram para a região em busca de trabalho e, quem sabe, de enriquecimento rápido.

A pesquisa historiográfica mais recente tem se mostrado original e criativa ao buscar documentos variados, desde lendas e mitos até organizações de antigas corporações (Darnton, 1986), na tentativa de melhor compreender a história. Nesse sentido a utilização de cartas como documentos de compreensão de determinados momentos históricos tem se mostrado de grande eficácia para análise e interpretação histórica desses momentos. As cartas revelam histórias de vida, registros de época, momentos únicos. Analisá-las e interpretá-las poderão fornecer subsídios para produzir uma história de colonização mais complexa.

Para tornar possível essa pesquisa, delimitamos alguns objetivos que possibilitarão o reconhecimento histórico da região bem como a ampliação do seu registro e interpretação, como já vem sendo realizado em outros trabalhos como teses, dissertações, artigos. Esse estudo vai permitir a conjunção entre a micro e a macro-história e para tanto trabalharemos com alguns objetivos:

- separar os documentos com vistas na compreensão do momento histórico da colonização do norte do Paraná

- analisar os documentos pessoais (correspondência ativa e passiva) e outros de George Craig Smith sob a perspectiva histórico-cultural 
- registrar o cotidiano dos "desbravadores", o que permitirá desvendar e construir parte da memória histórica da região

\section{DA TRADUÇÃO}

A primeira etapa do trabalho consiste em traduzir a correspondência pessoal ativa de George Craig Smith que compreende as seguintes etapas:

- quatro anos passados na Inglaterra completando seus estudos

- seis anos trabalhando para a CTNP, na região de Londrina

- oito anos passados nos Estados Unidos, de onde retorna como missionário

- tradução dos documentos de Arthur Hugh Miller Thomas, diretor da CTNP, a ele dirigidos

- tradução dos documentos de Eugenio Victor Larionoff, funcionário da CTNP

- tradução dos documentos de Willie da Fonseca Brabazon Davids, engenheiro da CTNP e, posteriormente, primeiro prefeito da cidade de Londrina

Esse trabalho de tradução refere-se à primeira etapa de elaboração do catálogo geral. A tradução acontece quando se tem um documento em língua 1, no caso, documentos escritos em inglês, e esses documentos são traduzidos em língua 2, no caso, para o português. Nesse sentido, o ato tradutório depende de procedimentos técnicos como aponta Barbosa (1990). Mas o ato de traduzir exige do tradutor mais do que conhecimentos linguiísticos. É necessário contextualizá-lo. Isso quer dizer que a tradução pode participar ativamente no processo de construir elementos de interpretação histórica. Ela seria, então, associada a acontecimentos da história da formação de um determinado povo ou grupo social, não havendo possibilidade de distinção entre textos originais e traduzidos. (Milton, 1993) Essa concepção de tradução deixa marcas no texto traduzido, pois ele se torna o produto da escolha das palavras, o produto de um processo dialógico num universo de vozes múltiplas.

Essa postura em relação ao ato tradutório será atualizada em cada documento que será traduzido, observando-se e respeitando-se o 
nível de linguagem (nível formal, informal) e a sintaxe; incluindo notas explicando o uso de certos termos no original que possam contextualizar o fato; cruzando com outras informações, quando possível, ou simplesmente indicando que não foi encontrada nenhuma informação complementar. Caso o documento exija, poder-se-á anexar outros textos traduzidos que sejam fontes para construir um processo de interpretação.

My dear mother and father

(...) So many buyers are coming now that we find very little time of our own. On Sunday 20 people came, last night 22 and tonight more 25 are expected. We are beginning to find the hotel here very small.

(...) We are expecting Mr. Ramos here very shortly with the director from England, Mr. Asquith. It will be interesting to see what decisions he will make on things here. The railway will be inaugurated at Jatahy next month, only $22 \mathrm{kms}$. from here and a telephone from there to the hotel at Londrina will be established. Things are becoming easier every day now. (...)

I do not suppose I will be able to get away from here for some time, firstly because of the vast amount of work and secondly because of my empty purse. Besides I want to buy some land if possible.

Dear mother and father I send with this uma grande e enorme saudades. Love from George

\section{Tradução}

Meus queridos pais

(...) Tantos compradores estão vindo agora que sobra pouco tempo para nós. No domingo vieram 20 pessoas, a noite passada 22 e esta noite esperamos mais 25 . Estamos começando a achar que o hotel está ficando muito pequeno. (...) 
(...) Nós estamos aguardando o senhor Ramos, ${ }^{(1)}$ que deverá chegar com o diretor da Inglaterra, senhor Asquith.(2) Será interessante ver quais as decisões que eles vão tomar aqui. A estrada de ferro será inaugurada em Jataizinho ${ }^{(3)}$ no mês que vem, somente 22 quilômetros daqui, e um telefone será instalado lá para fazer ligações com Londrina. As coisas estão ficando mais fáceis agora.(...)

Eu não acho que poderei sair daqui por algum tempo, primeiro por causa da quantidade imensa de trabalho e, segundo, porque eu não tenho dinheiro. Além disso, eu quero comprar um pouco de terra, se possível. ${ }^{(4)}$

Queridos pais, com essa carta envio uma grande e enorme saudades. ${ }^{(5)}$ Com carinho, George
Notas da pesquisa
(1) Identificar o senhor Ramos.
(2) Identificar o senhor Asquith.
${ }^{(3)}$ A cidade de Jataí mencionada na carta é a atual Jataizinho.
(4) George Craig Smith não conseguiu realizar esse sonho.
(5) Em português, no original.

\section{ANÁLISE E INTERPRETAÇÃO DOS DOCUMENTOS}

A documentação doada por George Craig Smith e depositada no Museu Histórico compõe-se, em sua maioria, de cartas. São cartas destinadas à família, mas a grande interlocutora é a mãe. Mesmo quando se dirige a todos da famúlia (pais e irmãos) o diálogo é realizado com a mãe.

Nos primeiros anos passados na Inglaterra, anos de estudo e formação, as cartas dão conta de tudo o que para ele se constituiu novidade na cultura européia, inglesa particularmente.

O trabalho que realizou na CTNP também é um período frutífero, onde escreve e relata todo o cotidiano do trabalho que coincide com os anos iniciais do desbravamento.

E, num terceiro momento, quando já afastado da CTNP, realizou um trabalho missionário em igrejas menonitas na região central do Brasil (Mato Grosso e Goiás). 
As primeiras cartas, sendo ele ainda adolescente na Inglaterra, retratam o dia-a-dia dos estudos, dos esportes que praticava e do reconhecimento do país que lhe era até então estranho. Nelas, Smith mostra a sua condição de bom aluno, aquele que tem que se esforçar para realizar e ser sempre o melhor. São cartas repetitivas, longas e descritivas, o que permite que se perceba a extrema solidão em que se encontrava longe da família. Demonstra uma grande preocupação com a saúde dos familiares, com a situação financeira dos pais e no relato de atividades que realiza, não esquecendo de enfatizar o seu sucesso pessoal.

Nessa fase (início da adolescência), Smith revela-se uma pessoa autocentrada, sobretudo quando escreve aos irmãos: "Eu ganhei", "Eu conheci", o que podemos considerar típica forma de comportamento de auto-afirmação de adolescente. Começa a perceber e a valorizar o dinheiro e demonstra uma grande preocupação com o trabalho e o valor que este possui.

De alguma forma, podemos detectar uma atitude preconceituosa em relação à questão sociorracial, quando, ao escrever para a família, manda abraços para todos, "except a criada", e, ao referir-se aos dias chuvosos em que jogava rugby, comenta que seus colegas ficavam parecidos com "pretos", "sujos como pretos".

A essa altura (entre 1922 e 1924) passa a escrever de modo bilíngüe, mas as duas línguas são escritas de modo incorreto. Percebese, nesse primeiro período de correspondência da Inglaterra, que George C. Smith compõe uma mentalidade à inglesa de forma cuidadosa, seja quanto ao cuidado no aprendizado de língua, seja no tocante ao aprendizado diário de viver como inglês: estudar bem, ser sempre um dos melhores da classe e nos esportes que praticava (rugby e cricket), além de apreender as diferenças do padrão cultural vivido no Brasil e daquele que passa a vivenciar na Inglaterra.

A observação do cenário - frio, neve, flores na primavera - é fator eloqüentemente registrado por Smith, que não deixa de acentuar as diferenças entre a Inglaterra e a "tropicalidade" brasileira.

O período em que trabalhou para a CTNP é profícuo em cartas e corresponde ao seu retorno ao Brasil, após concluir os estudos secundários na Inglaterra. O seu trabalho na CTNP é árduo e demanda muitas viagens por toda a região norte do Paraná, onde a companhia possui loteamentos. Em uma das cartas reclama das condições de trabalho e do pagamento da CTNP e fala da necessidade de arranjar 
outro emprego, talvez em São Paulo. Acha-se explorado pela companhia e desabafa: "Ficar no mato é ficar esquecido." Convém lembrar que a essa altura - 1931 - a região onde os loteamentos estão sendo vendidos é inóspita, praticamente só mata e vegetação nativa. (Certamente existiam índios na região, mas os documentos consultados omitem esse fato.)

Entretanto, ao visitar a fazenda de Willie Davids, fazendeiro em Cambará e representante da CTNP em Londrina, não deixa de falar do bom tratamento que recebe da família na fazenda. Relata o grande número de venda de terras e lotes e a procura deles por pessoas de várias nacionalidades como alemães, italianos, japoneses, poloneses, entre outros. (A CTNP desenvolveu um forte esquema de publicidade onde enfatizava a riqueza e a fertilidade das terras e a facilidade em comprá-las.)

A terceira fase onde ainda escreve muito, é quando se dedica ao trabalho missionário pela Igreja Menonita. As cartas são repletas de referências a Deus, à conversão, ao trabalho missionário, ao crescimento espiritual e aos planos de instalar um orfanato em São Paulo ou no Paraná, dada a experiência que adquiriu ao trabalhar com crianças. As condições precárias e a região "primitiva" são assuntos de suas cartas, e sonha com o momento de voltar para São Paulo e ver pessoas "bem vestidas e bonitas". Compara o local de trabalho onde está agora com o Paraná, onde tudo era melhor. Pensa em voltar ao Paraná, mas agora para um trabalho no plano espiritual — diz ser como um pecador que sai e retorna como um santo.

\section{CATALOGAÇÃO}

O objetivo maior deste projeto consiste na elaboração de um catálogo geral das cartas de George Craig Smith, constantes no seu arquivo do Museu Histórico Padre Carlos Weiss. Esse catálogo deverá sistematizar as informações sobre as cartas (eventualmente anexar outros documentos que possam dar subsídios para o conteúdo das cartas) para que estas se tornem de domínio público e de consulta para pesquisadores nas seguintes áreas: Literatura, História da Colonização e das Mentalidades, História Cultural, História Social, Arquivologia e Biblioteconomia. 
Para a consecução desse catálogo, seguiremos as seguintes etapas:

Montagem dos verbetes com os seguintes itens:

- classificação do tipo do documentos: carta, ofício, bilhete, telegrama, cartão de natal, cartão postal etc.

- a forma como o documento se apresenta: manuscrito, datilografado, rasgado, riscado, em língua estrangeira, tipo de papel, etc.

- local e data

- resumo do conteúdo dos documentos

- anexos e possíveis anotações

A partir da organização desses verbetes, será elaborado um catálogo em formato de livro dentro das normas de editoração da Biblioteca Nacional do Brasil, e contará ainda com apresentação e sumário. As fichas de catalogação terão os seguintes campos: nome da coleção, número de registro, autor/tradutor e destinatário, entre outros. Essas informações darão origem a outros índices que servirão para o pesquisador cruzar as informações que necessitar.

Esse catálogo deverá ser editado pela editora da Universidade Estadual de Londrina e a tiragem inicial será de 1.000 exemplares, que serão enviados a diversas instituições acadêmicas, de pesquisa e de patrimônio histórico. ${ }^{1}$

Esse trabalho de pesquisa pretende contribuir para aprofundar e disseminar o conhecimento sobre a história de Londrina, refletir sobre o padrão cultural que se instala nessa região colonizada por ingleses e que recebeu um grande contingente de diferentes nacionalidades que aqui vieram em busca do Eldorado. Esse Eldorado assumiu diversas conotações, e a partir desses documentos pesquisados será possível observar como se apresentam os microssistemas sociais e históricos que constituem o cenário da cultura da região norte do Paraná e especificamente de Londrina.

NOTA

1 Esse trabalho vem sendo realizado pelas bibliotecárias do Museu Histórico de Londrina: Rosangela R. Haddad e Ruth H. Shigaki Ueda. 


\section{BIBLIOGRAFIA}

ANDRADE, O. de S. \& COUTINHO, E. Editoração no Brasil. São Paulo: USP/ECA, 1971. $91 \mathrm{p}$.

ASSOCIAÇÃO DOS BIBLIOTECÁRIOS DO DISTRYTO FEDERAL. Editoração de publicações oficiais. Brasília: Departamento de Imprensa Nacional, 1987. 250p.

ATIENZA, C. A documentação jurídica. Rio de Janeiro: Achiamé, 1979.

BARBOSA, H.G. Procedimentos técnicos da tradução - uma nova proposta. Campinas: Pontes, 1990.

BELLOTTO, H.L. Arquivos permanentes: tratamento documental. São Paulo: T. A. Queiroz, 1991. 198p.

BELTRÃO, O. Correspondência: linguagem e comunicação. São Paulo: Atlas, 1983.

BRAJNOVIC, L. A diagramação e confecção de um periódico. São Paulo: USP/ECA, 1970. $31 \mathrm{p}$.

BURKE, P. (org.) A escrita da história: novas perspectivas. São Paulo: Unesp, 1992.

CHARTIER, R. A. História da cultura: entre práticas e representações. Rio de Janeiro: Bertrand Brasil, 1988.

CÓDIGO DE CATALOGAÇÃO ANGLO-AMERICANO. vol. 2. São Paulo: FEBAB, 1983. $2 \mathrm{v}$.

COHEN, D.M. O consumidor da informação documentária: o usuário de sistemas documentários visto sob a lente da análise documentaria. São Paulo, 1995. Dissertação (Mestrado em Biblioteconomia) - Universidade de São Paulo.

DARNTON, Robert. O grande massacre de gatos. Rio de Janeiro: Graal, 1986.

FERRAZ, W. Relação de assuntos para cabeçalhos de fichas. 5.ed. Rio de Janeiro: Freitas Bastos, 1977. 301p.

FERRERIA, M. de M. \& AMADO, Janaina. (orgs) Usos e abusos da história oral. Rio de Janeiro: Fund. Getúlio Vargas, 1996.

FERRO, M. A história vigiada. São Paulo: Martins Fontes, 1989.

GINZBURG C. A micro-história e outros ensaios. Rio de Janeiro: Bertrand Russel, 1989

HUNT, L.A. A nova história cultural. São Paulo: Martins Fontes, 1992.

JARDIM, J.M. As novas tecnologias da informação e o futuro dos arquivos. Estudos Históricos, Rio de Janeiro, v.5, n.10, p.251-260, 1992.

KNYCHALA, A. C. Editoração. Rio de Janeiro: Presença, 1981. 66p.

KOTAIT, I. Editoração científica. São Paulo: Ática, 1981. 116p. (Ensaios, 70)

LE GOFF, J. História e memória. Campinas: Unicamp, 1990.

(org.) A história nova. São Paulo: Martins Fontes, 1992.

et al. Histoire et imaginaire. Paris: Poiesis, 1986.

LONGMAN. Dictionary of english language and culture.

Rev. Mediações, Londrina, v. 5, n. 1, p. 157-167, jan./jun. 2000 
MALUF, M. Ruídos da memória. São Paulo: Siciliano, 1995.

MEMÓRIA, história, historiografia. Revista Brasileira de História n. 25 e 26, São Paulo: Marco Zero, 1993.

MILTON, J. O poder da traduçāo. São Paulo: Ars Poetica, 1993.

MUNDO DA IMAGEM: processamento eletrônico de imagens para completo gerenciamento da informação. Jornal do CENADEM. São Paulo, s.d.

ODALIA, N. O saber e a história: George Duby e o pensamento historiográfico contemporâneo. São Paulo: Brasiliense, 1994.

OLIVEIRA, D.A. Arquivo e documento. Revista do Arquivo Municipal. Memória Cultural. São Paulo, n.200, p.113-148, 1992.

PARANÁ NORTE. Londrina-PR. 1934-1953.

POLÍTICA de preservação de acervos institucionais. Rio de Janeiro: CNPq/MAST, Museu da República/IPHAN MINC, 1995. 33p.

RAJER, A. Equipamentos usados em laboratórios para restauração. Estados Unidos: s.n, 1985.

UNIVERSIDADE FEDERAL FLUMINENSE. Núcleo de Documentação. Manual de normalização. Niterói: UFF/NDC. 302p.

VEYNE, P. Como se escreve a história. Lisboa: Edições 70, 1971.

VOVELLE, M. Imagens e imaginário na história: fantasmas e certezas nas mentalidades desde a Idade Média até o século XX. São Paulo: Ática, 1997.

WEBSTER'S THIRD NEW INTERNATIONAL DICTIONARY. 3v.

RESUMO

Os primeiros desbravadores que vieram para a região norte do Paraná a fim de trabalhar, seja na abertura de loteamentos para a Companhia de Terras Norte do Paraná (CTNP), seja na agricultura e outros serviços que se apresentassem, doaram seus objetos e documentos pessoais ao Museu Histórico Padre Carlos Weiss de Londrina. O presente trabalho refere-se à documentação de George Craig Smith, primeiro funcionário da CTNP. Essa documentação compõe-se, na sua maioria, de correspondência ativa e passiva, escrita em inglês. O nosso trabalho é, pois, organizar, traduzir e analisar essa documentação e publicá-la em forma de catálogo. A finalidade será possibilitar aos estudiosos do cotidiano histórico de Londrina e região o acesso à pesquisa

Palavras-chave: história; catálogo; documentos históricos; correspondência.

\section{ABSTRACT}

The first settlers who came to colonize the north region of Paraná State kept the personal documents and donated part of them to the Museum of History Padre Carlos Weiss in Londrina. Most documents from George Craig Smith, who worked for Companhia de Terras Norte do Paraná (CTNP), were written in English and were not translated into 
Portuguese and analysed. There are important information to explain the process of the colonization of this region in them. To translate the letters, organize all the documents and then publish a cataloque is the aim of the research project that has been carrying on by professors, librarians and students from the State University of Londrina.

Key words: History; catalogue; historical documents; letters.

Raimunda de Brito Batista é professora do Departamento de Ciências Sociais da UEL e Regina Maria G. Domiciano é professora do Departamento de Letras Vernáculas da UEL. 